\title{
DEVELOPMENT AND VALIDATION OF SENSITIVE LC-ESI-MS/MS METHOD FOR THE SIMULTANEOUS ESTIMATION OF DAPAGLIFLOZIN AND SAXAGLIPTIN IN HUMAN PLASMA
}

\author{
ADLURI PHANINDRA1* ${ }^{*}$ Y. SHRAVAN KUMAR² \\ ${ }^{1}$ Research Scholar, Mewar University, Chittorgarh, Rajasthan, India, ${ }^{2}$ Research Supervisor, Mewar University, Chittorgarh, Rajasthan, India \\ Email: adluriphanindra@gmail.com
}

Received: 08 Dec 2018 Revised and Accepted: 22 Feb 2019

\section{ABSTRACT}

Objective: To develop and validate a sensitive liquid chromatography-electrospray ionization-tandem mass spectrometric (LC-ESI-MS/MS) technique for the quantification of dapagliflozin and saxagliptin in plasma by linagliptin as internal standard.

Methods: Chromatography was achieved on hypersil $\mathrm{C}_{18}(50 \mathrm{mmx} 4 \mathrm{~mm}) 5 \mu$ analytical column with $0.1 \%$ formic acid and acetonitrile $(25: 75 \mathrm{~V} / \mathrm{V})$ as mobile phase at $0.7 \mathrm{ml} / \mathrm{min}$ flow rate. Dapagliflozin, saxagliptin, and linagliptin were detected at $\mathrm{m} / \mathrm{z} 409.14 / 135.0, \mathrm{~m} / \mathrm{z} 316.2 / 180.13$ and $\mathrm{m} / \mathrm{z}$ 472.54/456.21 respectively. Drugs and internal standard were extracted by LLE (liquid-liquid extraction).

Results: Developed technique was validated over $0.5-1500.0 \mathrm{ng} / \mathrm{ml}$ linear concentration range for dapagliflozin and $2.00-2000.0 \mathrm{ng} / \mathrm{ml}$ for saxagliptin. This method established with intra-batch and inter-batch precision within 2.44-8.12\% and 1.25-7.14 \% for dapagliflozin and 1.84-7.5 \% and 1.02-6.00\% for saxagliptin. This method established with intra-batch and inter-batch accuracy for dapagliflozin within 98.86-103\% and 96.98$102 \%$ respectively and for saxagliptin within 98.05-109.06\% and 97.00-104.00\% respectively.

Conclusion: Both dapagliflozin and saxagliptin were stable during three freeze-thaw cycles, long term and bench-top stability studies. The developed method was useful for the routine analysis of dapagliflozin and saxagliptin simultaneously in plasma samples.

Keywords: Dapagliflozin, Saxagliptin, LC-ESI-MS/MS, Validation, Precision and Accuracy

(C) 2019 The Authors. Published by Innovare Academic Sciences Pvt Ltd. This is an open-access article under the CC BY license (http://creativecommons.org/licenses/by/4.0/) DOI: http://dx.doi.org/10.22159/ijpps.2019v11i4.31249

\section{INTRODUCTION}

Dapagliflozin (DPG) is useful in controlling diabetes mellitus type-2 and improves glycemic control when mixed with diet and exercise. IUPAC name of the drug is $(2 S, 3 R, 4 R, 5 S, 6 R)-2$-[4-Chloro-3-(4ethoxybenzyl) phenyl]-6-(hydroxymethyl) tetrahydro- $2 H$-pyran3,4,5-triol [1]. Drug inhibits $\mathrm{Na}^{+} /$glucose co-transporter-2, which inhibits the kidney glucose reabsorption. Using dapagliflozin leads to heavy glycosuria (glucose excretion in the urine), which can lead to weight loss and tiredness [2].

Chemically Saxagliptin (SXG) designated as $(1 S, 3 S, 5 S)-2-[(2 S)-2-$ amino-2-(3-hydroxy-1-adamantyl) acetyl]-2-azabicyclo [3.1.0] hexane-3-carbonitrile. It belongs to the diabetes medications class called dipeptidyl peptidase-4 (DPP-4) blockers. DPP-4 damages incretin hormones which belongs to an enzyme [3]. Saxagliptin reduces the metobolism of incretin hormones (as DPP-4 inhibitor) and in human body, the concentration of these hormones will increases. This increase in hormones is responsible for the beneficial activities of saxagliptin and increases insulin creation with response to diet and reduces the gluconeogenesis in liver. DPP-4's action in the regulation of blood glucose is thought to be through the breakdown of GIP and GLP-1. Because these hormones are active in response to high blood glucose levels (and are less reactive in response to low blood glucose), the risk of dangerously hypoglycemia is very less with saxagliptin monotherapy $[4,5]$.

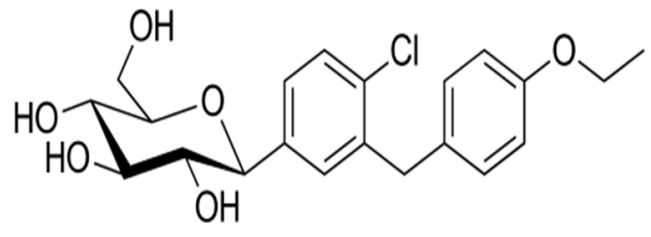

Fig. 1: Structure of dapagliflozin

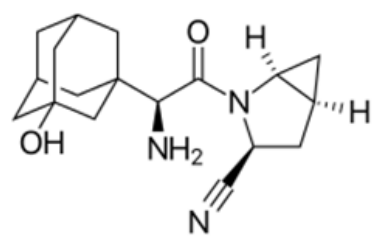

Fig. 1: Structure of saxagliptin

Literature survey of these drugs revealed several analytical techniques for the determination of these drugs in formulations which includes the methods such as UV-spectroscopy [6, 7], highperformance liquid chromatography (HPLC) [8-11] and LC-MS/MS [13]. Present research work aimed to develop specific and accurate LC-MS/MS method with low retention time.

\section{MATERIALS AND METHODS}

\section{Reagents and chemicals}

DPG, SXG and linagliptin (Internal Standard) of reference grade were provided by MSN Labs, Hyderabad as gift samples. Hypersil $\mathrm{C}_{18}(50$ mmx4 mm) $5 \mu$ analytical columns were procured from Thermo Fischer Pvt. Ltd. Acetonitrile and methanol of HPLC-grade were procured from S. D-Fine Chemicals. Water used in present work was purified by means of Milli-Q water purification systems from Millipore. Analytical grade formic acid was bought from E. Merck Mumbai, India.

\section{Instrumentation}

The LC-ESI-MS/MS system comprised a Liquid Chromatography (Shimadzu LC10) from Shimadzu combined to an MS/MS (API-3000) from Applied Biosystems Sciex, Canada, furnished with a Turbo-Ion Spray source for ion production. Monitoring of data and integration of chromatograms were processed by Analyst Software of Applied Biosystems, version-1.4.1. 


\section{Liquid chromatography}

The components were eluted by infusing the sample solution into hypersil $\mathrm{C}_{18}(50 \mathrm{mmx} 4 \mathrm{~mm}) 5 \mu \mathrm{m}$ analytical column at $45^{\circ} \mathrm{C}$ using a mobile phase composition of $0.1 \%$ formic acid and acetonitrile $25: 75$ $\mathrm{v} / \mathrm{v})$. Mobile phase degasification was performed by filtration $(0.5 \mu$ filter paper) and sonication of the mobile phase. Analytes were separated with isocratic elution with a flow of mobile phase at $0.7 \mathrm{ml} / \mathrm{min}$ through analytical column. The autosampler temperature was adjusted to $5{ }^{\circ} \mathrm{C}$.

\section{Mass scanning optimization}

DPG and SXG stock solutions were prepared by dissolving the components in HPLC-grade methanol. Further dilutions were made with the solvent mixture of methanol and water in the composition of $50: 50 \mathrm{v} / \mathrm{v}$. The analytes were analysed by MRM (multiple reaction monitoring) of the transition pairs of transitions $\mathrm{m} / \mathrm{z} 409.14 / 135.0$, $\mathrm{m} / \mathrm{z} 316.2 / 180.13$ and $\mathrm{m} / \mathrm{z} 472.54 / 456.21$ for DPG, SXG and internal standard (IS) respectively.

\section{Mass spectrometry}

The electro-spray interface heater (IHE) was switch to on mode and Ion spray (IS) Voltage was fixed at $4500 \mathrm{~V}$ for ionization. The curtain gas (nitrogen) was tuned to constant fig. of 12 units and the temperature of source (at set point) was $500^{\circ} \mathrm{C}$. The mass instrument parameters were adjusted to achieve high sensitivity at unit resolution. The MRM mode for DPG, SXG and IS were detected at m/z 409.14/135.0, m/z 316.2/180.13 and $\mathrm{m} / \mathrm{z} 472.54 / 456.21$ respectively.

\section{Preparation of quality control and calibration standards}

DPG and SXG stock solution of were prepared in 70\% methanol at a concentration of $1000 \mu \mathrm{g} / \mathrm{ml}$. Calibration standards for DPG were $0.5,1$, 20, 40, 200, 400, 800, 1200 and $1500 \mathrm{ng} / \mathrm{ml}$ and for SXG were 2, 4, 20, 100, 300, 600, 1200, 1500 and $2000 \mathrm{ng} / \mathrm{ml}$. These solutions were prepared from stock solution by serial dilution method with $70 \%$ methanol. High, medium and low concentration quality control (QC) standards for DPG (1200, 800 and $1 \mathrm{ng} / \mathrm{ml})$ and for SXG (1500, 900 and $4 \mathrm{ng} / \mathrm{ml}$ ) were prepared in the similar way. The stock solution of linagliptin IS $(1000 \mu \mathrm{g} / \mathrm{ml})$ was also prepared in $70 \%$ methanol and further, it was diluted to $5.0 \mathrm{ng} / \mathrm{ml}$ concentration. All solutions were retained in a freezer at $2-8^{\circ} \mathrm{C}$ until actual sample analysis.

\section{Sample preparation}

To prepare sample solution $0.30 \mathrm{ml}$ of plasma was transferred in to a $10 \mathrm{ml}$ tube and $50 \mu \mathrm{l}$ of IS $(50.0 \mathrm{ng} / \mathrm{ml})$ was added. The resulting solution vortexed for $30 \mathrm{~s}$ and further $5 \mathrm{ml}$ of ethyl acetate and butyl methyl ether solvent was mixed and vortexed for $10 \mathrm{~min}$ in a centrifuge at $3000 \mathrm{rpm}$. Resulting solution was evaporated by the application of steam of nitrogen and water bath. Reconstitute with $250 \mu \mathrm{l}$ of mobile phase mixture and shake for $2 \mathrm{~min}$. Finally, the resulting solution was transferred into an auto-sampler vial and infused into a liquid chromatographic system.

\section{Validation of analytical method}

Method validation was executed according to Food and Drug Administration guidelines on Bioanalytical Method Validation [14-18].

\section{Selectivity and specificity}

Potential nosiness between analyte and endogenous matrix constituents was examined by the analysis of 6 lots blank plasma from different source. From each lot, a double blank and a LLOQ sample were prepared, infused and analysed [16, 19]. To determine potential nosiness between IS and analytes, blank sample spiked with analytes separately (at the upper limit of quantification) and IS were infused and estimated. Peak areas of components co-eluting with analytes should be $<20 \%$ of LLOQ sample peak area. Peak areas of co-eluents of IS, should be $<5 \%$ of the average IS peak area. The measured concentrations of the LLOQ standard samples should be $<20 \%$ from the nominal concentrations.

\section{Precision and accuracy}

The precision and accuracy of the assay method were assessed by analysing 5 duplicates of quality control samples of DPG and SXG at the concentration level of LLOQ, LQC, MQC and HQC standards in 3 analytical runs. Inter-assay accuracy was determined as the relative difference between the average measured concentration after 3 runs and the nominal concentration $[17,20]$. Accuracy should be $\pm 20 \%$ for the LLOQ and $\pm 15 \%$ for the remaining concentrations. Inter and Intraassay precisions were denoted by coefficient of variation (\%CV), which should be $<20 \%$ for the LLOQ and $<15 \%$ for the remaining standards.

\section{Linearity}

For the estimation of linearity, calibration curves of nine points (non-zero standards) were used. Nine non-zero points of $0.5,1,20$, $40,200,400,800,1200$ and $1500 \mathrm{ng} / \mathrm{ml}$ for DPG and 2, 4, 20, 100, $300,600,1200,1500$ and $2000 \mathrm{ng} / \mathrm{ml}$ for SXG were analysed. The information from three accuracy and precision lots was considered to analyse goodness of fit using $1 / x$ and $1 / x^{2}$ weighing factor. Deviation from nominal concentration should be within $\pm 20 \%$ for LLOQ and within $\pm 15 \%$ for remaining concentrations. Linear coefficient of correlation $\left(\mathrm{r}^{2}\right)$ should be $\geq 0.98$.

\section{Matrix factor}

Matrix Factor (MF) of analytes in plasma were processed at HQC and LQC levels after extraction in six different blank matrix batches. Simultaneously six duplicates of equivalent neat quality control samples were prepared and estimated [18-22]. Assess the MF for analytes and IS in each batch by the application of formula:

Matrix Factor = (Peak area in the presence of matrix components $/$ Average peak area in aqueous samples).

\section{Recovery}

Recoveries were determined by matching the mean peak area of 6 extracted LQC, MQC and HQC samples (1.0, 800.0 and $1200.0 \mathrm{ng} / \mathrm{ml}$ for DGP and 4.0, 900.0 and $1500.0 \mathrm{ng} / \mathrm{ml}$ for SXG) to average peak area of 6 spiked samples with the same quantities of high, medium and low DGP/SXG quality control samples.

\section{Dilution integrity}

The concentration of the drug above upper limit of quantification (ULOQ) was prepared and precision and accuracy parameters were determined. The percentage of nominal concentration should be $\pm 15 \%$.

\section{Autosampler stability}

To estimate autosampler stability, 6 sets of quality control standards (LQC and HQC) were prepared and kept in an autosampler. These standard samples were infused after $24 \mathrm{~h}$ and were estimated against freshly spiked calibration standards. The findings when compared with nominal concentrations, should be within $\pm 15 \%$.

\section{Stability}

LQC and HQC samples $(n=6)$ were regained from the freezer after 3 freeze and thaw cycles. Samples were stored at- $30{ }^{\circ} \mathrm{C}$ in 3 cycles of $24,48,72 \mathrm{~h}$. For the long term stability of DPG and SXG in QC samples were also estimated by analysis after 4 mo of storage at-25 ${ }^{\circ} \mathrm{C}$ and-70 ${ }^{\circ} \mathrm{C}$. Bench-top stability was assessed for $7 \mathrm{~h}$ period with standard concentrations [23-25]. Stability solutions were prepared and extracted along with freshly spiked calibration standards. The accuracy and precision of the stability solutions should be $\pm 15 \%$ of their nominal concentrations.

\section{RESULTS AND DISCUSSION}

\section{Method development and validation}

A sample extraction procedure was employed in the extraction of drugs and internal standard from plasma samples. Chromatographic conditions were improved through several trials to attain best resolution and increase signal to noise ratio of analytes and IS. The Mass instrument conditions were optimized by infusing the solution directly into electrospray ionization source of the mass system.

After MRM transitions were adjusted, the organic portion of mobile phase was increased to gain a selective and rapid LC technique. A good resolution and elution were attained using an isocratic mobile phase composition of $0.1 \%$ formic acid and acetonitrile $(25: 75 \mathrm{v} / \mathrm{v})$, at $0.7 \mathrm{ml} / \mathrm{min}$ flow rate. 


\section{Selectivity}

Six different batches of blank plasma were selected and interference of endogenous substances at retention time of analytes and internal standard were analysed. Interference of matrix components were not observered at the RT and m/z of DPG and SXG and internal standard in all the batches screened fig. 3, elucidates the representative chromatogram for blank and LLOQ.
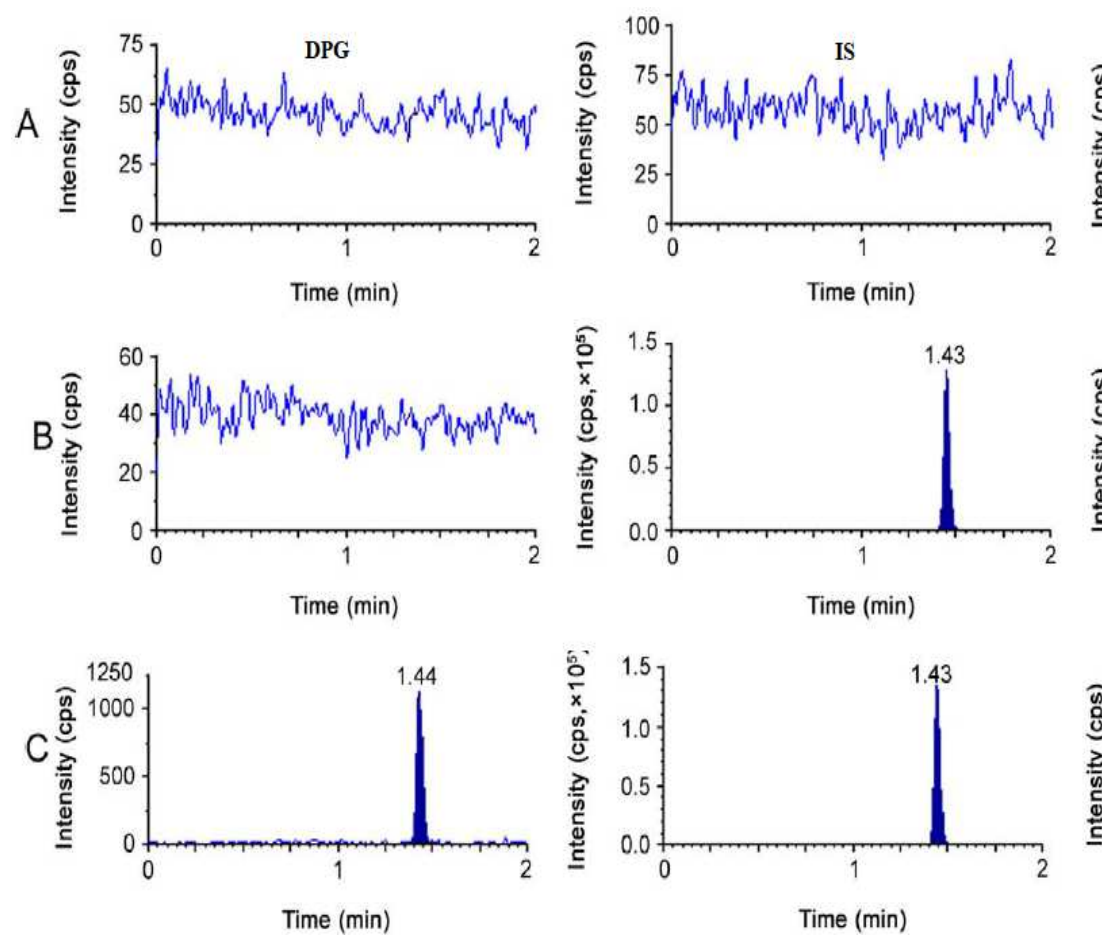

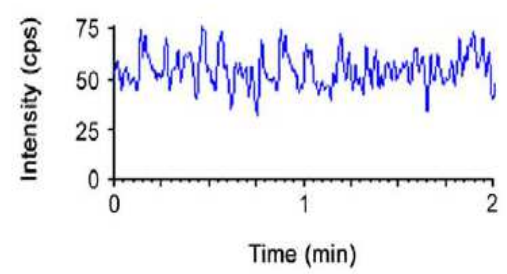

Fig. 3: Typical chromatograms of DPG, SXG and IS in A) Blank plasma, B) Blank plasma spiked with IS and C) Spiked with LLOQ level

\section{Precision and accuracy}

Precision and accuracy of the method was estimated by calculating the intra-day and inter-day batch deviations of three quality control samples in 6 replicates: 1.0, 800.0 and 1200.0 $\mathrm{ng} / \mathrm{ml}$ for DPG and 4.0, 900.0 and $1500.0 \mathrm{ng} / \mathrm{ml}$ for SXG as represented in table 1.

Intra-day precision and accuracy for DPG ranged from $2.44-8.12 \%$ and $98.86-103 \%$ respectively and for SXG ranged from 1.84-7.5\% and 98.05-109.06 \% respectively. Inter-day precision and accuracy fluctuated between $1.25-7.14 \%$ and $96.98-102 \%$ respectively for DPG and 1.02-6.00\% and 97.00-104.00 \% respectively for SXG. These results indicates that the method was accurate, reliable and reproducible as all the parameters were within the limit of $<15 \%$ and $\pm 15 \%$ for precision and accuracy respectively for LQC, MQC and HQC and $<20 \%$ for LLOQ.

\begin{abstract}
Linearity
Linearity curve was established in concentration range of 0.5 $1500.0 \mathrm{ng} / \mathrm{ml}$ for DPG and $2.0-2000.0 \mathrm{ng} / \mathrm{ml}$ for SXG respectively in human plasma with a correlation coefficient of $\left[\mathrm{r}^{2}\right] \geq 0.99$. The mean slope and intercept of regression equations were 0.006521 and 0.002564 for DPG and 0.01652 and-0.03215 for SXG. Linearity was found to be acceptable and reproducible. The estimated correlation coefficients for DPG and SXG were greater than 0.9970 and 0.9960 respectively for all the calibration curves (table 2).
\end{abstract}

\section{Matrix factor}

The calculated \%Coefficient of variance values for HQC and LQC samples were $0.35 \%$ and $1.89 \%$ respectively. The findings were within the acceptable limit. The results were shown in the table 3.

Table 1: Intra-day and inter-day accuracy and precision of DPG and SXG

\begin{tabular}{|c|c|c|c|c|c|c|}
\hline \multirow{2}{*}{$\begin{array}{l}\text { Nominal } \\
\text { (ng/ml) }\end{array}$} & \multicolumn{3}{|l|}{ Intra-day ${ }^{a}$} & \multicolumn{3}{|l|}{ Inter-day ${ }^{a}$} \\
\hline & $\begin{array}{l}\text { Mean } \\
\text { observed }(\mathrm{ng} / \mathrm{ml})\end{array}$ & $\begin{array}{l}\text { Precision } \\
\text { (\%) }\end{array}$ & $\begin{array}{l}\text { Mean } \\
\text { accuracy (\%) }\end{array}$ & $\begin{array}{l}\text { Mean } \\
\text { observed }(\mathrm{ng} / \mathrm{ml})\end{array}$ & $\begin{array}{l}\text { Precision } \\
\text { (\%) }\end{array}$ & $\begin{array}{l}\text { Mean } \\
\text { accuracy (\%) }\end{array}$ \\
\hline \multicolumn{7}{|c|}{ Dapagliflozin } \\
\hline 1.0 & 1.08 & 8.12 & 102.84 & 0.94 & 7.14 & 98.12 \\
\hline 800.0 & 795.95 & 3.98 & 98.861 & 789.32 & 6.32 & 96.98 \\
\hline 1200.0 & 1209.71 & 2.44 & 101.94 & 1206.64 & 1.25 & 101.18 \\
\hline \multicolumn{7}{|c|}{ Saxagliptin } \\
\hline 4.0 & 4.09 & 7.44 & 109.06 & 4.06 & 5.56 & 103.11 \\
\hline 900.0 & 892.05 & 1.84 & 98.05 & 896.81 & 3.41 & 98.15 \\
\hline 1500.0 & 1507.60 & 1.87 & 102.51 & 1509.33 & 1.02 & 102.21 \\
\hline
\end{tabular}

$\mathrm{a}=6$ replicates 
Table 2: Spiked plasma concentration and RSD (\%) for DPG and SXG

\begin{tabular}{|c|c|c|c|}
\hline Plasma concentration $(\mathrm{ng} / \mathrm{ml})$ & Concentration measured (mean) (ng/ml) $\pm S D(n)$ & \% RSD & $\%$ Accuracy \\
\hline \multicolumn{4}{|l|}{ Dapagliflozin } \\
\hline 0.5 & $0.48 \pm 0.159$ & 3.71 & 96.22 \\
\hline 1.0 & $1.96 \pm 0.266$ & 2.77 & 97.10 \\
\hline 20.0 & $20.51 \pm 0.912$ & 4.80 & 103.45 \\
\hline 40.0 & $40.41 \pm 2.501$ & 2.37 & 101.41 \\
\hline 200.0 & $211.52 \pm 7.234$ & 2.23 & 109.75 \\
\hline 400.0 & $408.42 \pm 9.367$ & 1.53 & 102.21 \\
\hline 800.0 & $814.23 \pm 7.208$ & 0.74 & 105.45 \\
\hline 1200.0 & $1220.51 \pm 0.562$ & 1.52 & 101.85 \\
\hline 1500.0 & $1540.41 \pm 2.501$ & 0.85 & 104.37 \\
\hline \multicolumn{4}{|l|}{ Saxagliptin } \\
\hline 2.0 & $2.13 \pm 0.056$ & 2.45 & 102.43 \\
\hline 4.0 & $3.98 \pm 0.091$ & 3.12 & 99.14 \\
\hline 20.0 & $20.85 \pm 0.194$ & 4.94 & 104.52 \\
\hline 100.0 & $104.97 \pm 0.842$ & 4.41 & 104.97 \\
\hline 300.0 & $304.21 \pm 1.021$ & 1.54 & 102.38 \\
\hline 600.0 & $610.04 \pm 1.335$ & 1.11 & 102.03 \\
\hline 1200.0 & $1189.81 \pm 0.914$ & 0.47 & 94.90 \\
\hline 1500.0 & $1482.97 \pm 0.842$ & 3.52 & 94.96 \\
\hline 2000.0 & $1978.21 \pm 1.021$ & 2.14 & 93.31 \\
\hline
\end{tabular}

$\mathrm{n}=6$ replicates; $\mathrm{SD}=$ Standard deviation; $\mathrm{RSD}=$ Relative standard deviation

Table 3: Matrix effect data for DPG and SXG

\begin{tabular}{|c|c|c|c|c|}
\hline \multirow[b]{2}{*}{ ID } & \multicolumn{2}{|c|}{ Dapagliflozin } & \multicolumn{2}{|c|}{ Saxagliptin } \\
\hline & LQC & HQC & LQC & HQC \\
\hline Actual concentration (ng/ml) & 1 & 1200 & 4 & 1500 \\
\hline 1 & 0.99 & 1189 & 3.89 & 1479 \\
\hline 2 & 0.95 & 1195 & 3.95 & 1489 \\
\hline 3 & 0.95 & 1206 & 3.86 & 1472 \\
\hline 4 & 1.09 & 1210 & 4.5 & 1510 \\
\hline 5 & 1.02 & 1195 & 4.06 & 1508 \\
\hline 6 & 0.96 & 1208 & 3.95 & 1492 \\
\hline Mean & 0.99 & 1200.5 & 4.035 & 1491.67 \\
\hline$\pm \mathrm{SD}$ & 0.05 & 7.85 & 0.28 & 13.89 \\
\hline$\% \mathrm{CV}$ & 5.02 & 0.65 & 5.38 & 0.93 \\
\hline$\%$ Accuracy & 96.75 & 99.66 & 100.05 & 99.4 \\
\hline
\end{tabular}

$\mathrm{SD}=$ Standard deviation; $\mathrm{CV}=$ Coefficient of variation

\section{Recovery}

The percentage recovery was estimated by evaluating the absolute peak area of DPG, SXG and IS from a plasma sample prepared according to the method of analysis. The extent of retrieval of drug analyte and of the internal reference standard should be consistent, precise and reproducible. The mean overall recovery of DPG and IS was found to be $96.27 \%$ and $96.13 \%$ respectively. The mean overall recovery of SXG and IS was found to be $89.52 \%$ and $94.42 \%$ respectively.

\section{Dilution integrity}

DPG and SXG were diluted up to 20 fold by blank plasma and were analyzed with spiked samples above the upper limit of the calibration standard and samples with the highest concentration. The $\%$ nominal was within \pm 15 and the observed precision was within $<15 \%$. This demonstrates that the sample can be diluted up to 20 times and yet the results are predictable and reproducible.

Table 4: Stability data for DPG and SXG

\begin{tabular}{|c|c|c|c|c|c|c|c|c|c|}
\hline \multirow[t]{2}{*}{ Drug } & \multirow[t]{2}{*}{$\begin{array}{l}\text { Concentration } \\
\text { (ng/ml) }\end{array}$} & \multicolumn{2}{|c|}{ Bench-top stability } & \multicolumn{2}{|c|}{ Autosampler stability } & \multicolumn{2}{|l|}{$\begin{array}{l}\text { Freeze-thaw } \\
\text { stability }\end{array}$} & \multicolumn{2}{|l|}{$\begin{array}{l}\text { Long-term } \\
\text { stability }\end{array}$} \\
\hline & & $\begin{array}{l}\text { mean } \pm \text { SD } \\
(\mathrm{ng} / \mathrm{ml})\end{array}$ & $\% \mathrm{CV}$ & $\begin{array}{l}\operatorname{mean} \pm S D \\
(\mathrm{ng} / \mathrm{ml})\end{array}$ & $\% \mathrm{CV}$ & $\begin{array}{l}\text { mean } \pm \text { SD } \\
(\mathrm{ng} / \mathrm{ml})\end{array}$ & $\% \mathrm{CV}$ & $\begin{array}{l}\text { mean } \pm S D \\
(\mathrm{ng} / \mathrm{ml})\end{array}$ & $\% \mathrm{CV}$ \\
\hline \multirow[t]{2}{*}{$\mathrm{DPG}$} & 1 & $1 \pm 0.14$ & 8.3 & $1 \pm 0.16$ & 4.5 & $1 \pm 0.09$ & 3.45 & $1 \pm 0.2$ & 8.2 \\
\hline & 1200 & $1200 \pm 8.12$ & 7.2 & $1200 \pm 7.20$ & 7.5 & $1200 \pm 9.01$ & 5.21 & $1200 \pm 9.0$ & 4.4 \\
\hline \multirow[t]{2}{*}{ SXG } & 4 & $4 \pm 0.75$ & 9.1 & $4 \pm 0.95$ & 8.2 & $4 \pm 0.25$ & 5.9 & $4 \pm 0.31$ & 6.3 \\
\hline & 1500 & $1500 \pm 7.58$ & 6.4 & $1500 \pm 7.20$ & 6.1 & $1500 \pm 9.01$ & 4.6 & $1500 \pm 9.0$ & 5.4 \\
\hline
\end{tabular}

$\mathrm{SD}=$ Standard deviation; $\mathrm{CV}=$ Coefficient of variation.

\section{Stability studies}

The stability data of DPG and SXG, which includes autosampler, longterm, freeze thaw and bench-top were within the acceptance limit. Results were revealed in table 4.

\section{CONCLUSION}

In this research article an LC-ESI-MS/MS technique for the quantification of DPG and SXG in plasma was effectively developed and validated. All the validation parameters: selectivity, accuracy, 
precision, recovery, stability, matrix effect, and dilution integrity were within the acceptance limit. The samples for LC-ESI-MS/MS analysis were processed by liquid-liquid extraction technique. The validated method is also highly sensitive, reliable over the other techniques like GC and HPLC. The pharmaceutical formulations containing these combinations were successfully estimated by this method routinely in human plasma.

\section{AUTHORS CONTRIBUTIONS}

All the authors contributed equally to this manuscript

\section{CONFLICTS OF INTERESTS}

The authors claim that they have no conflict of interest

\section{REFERENCES}

1. Obermeier $\mathrm{M}$, Yao $\mathrm{M}$, Khanna $\mathrm{A}$, Koplowitz $\mathrm{B}$. In vitro characterization and pharmacokinetics of dapagliflozin (BMS512148), a potent sodium-glucose cotransporter type II inhibitor, in animals and humans. Drug Metab Dispos 2010;38:405-14.

2. Kasichayanula S, Liu X, Lacreta F, Griffen SC, Boulton DW. Clinical pharmacokinetics and pharmacodynamics of dapagliflozin, a selective inhibitor of sodium-glucose cotransporter type 2. Clin Pharmacokinet 2014;53:17-27.

3. Scirica B, Bhatt DL, Braunwald E. Saxagliptin and cardiovascular outcomes in patients with type 2 diabetes mellitus. New England J Med 2013;369:1317-26.

4. Ali S, Fonseca V. Saxagliptin overview: special focus on safety and adverse effects. Expert Opin Drug Safety 2013;12:103-9.

5. Dhillon S, Weber J. Saxagliptin. Drugs 2009;69:2103-14.

6. Raveendra BG, Kumar RA, Shaheen SD, Greeshma A, Satyanarayana M. A novel stability-indicating method for the simultaneous estimation of saxagliptin and dapagliflozin in rat serum by using UV spectroscopy. Pharm Anal Acta 2018;9:2-5.

7. Gajanan Vithoba Mante, Krishna Radheshyam Gupta, Atul Tryambakrao Hemke. Estimation of dapagliflozin from its tablet formulation by UV-spectrophotometry. Pharm Methods 2017;8:102-7.

8. Patel PD, Pandya SS. Validated RP-HPLC method for simultaneous estimation of dapagliflozin and saxagliptin hydrochloride in the tablet dosage form. Int J Pharm Res Scholars 2018;7:32-41.

9. Deepan Thiyagarajan, Dasaratha Dhanaraju. Stability indicating HPLC method for the simultaneous determination of dapagliflozin and saxagliptin in bulk and tablet dosage form. Curr Issues Pharm Med Sci 2018;31:39-43.

10. Sarath Nalla, Seshagiri Rao JVLN. A stability indicating RP-HPLC method for simultaneous estimation of dapagliflozin and saxagliptin in combined tablet dosage forms. Inventi Rapid: Pharm Anal Quality Assurance 2017;4:1-11.

11. Sharmila Donepudi. Simultaneous estimation of saxagliptin and dapagliflozin in human plasma by validated HPLC-UV method. Turkish J Pharm Sci 2018;1-23. Doi:10.4274/tjps.46547.

12. Ghadir A Khalil, Salama Ismail, Gomaa Mohammed, Helal Mohammed. Validated RP-HPLC method for simultaneous determination of canagliflozin, dapagliflozin, empagliflozin and metformin. Int J Pharm Chem Biol Sci 2018;8:1-13.

13. Batta N, Pilli NR, Derangula VR. A rapid and sensitive LC-MS/MS assay for the determination of saxagliptin and its active metabolite 5-hydroxy saxagliptin in human plasma and its application to a pharmacokinetic study. Drug Res 2015;65:133-40.

14. Shuchi Dave Mehta, Sarvesh Paliwal. Phytochemical analysis, liquid chromatography, and mass spectroscopy and in vitro anticancer activity of annona squamosa seeds linn. Asian J Pharm Clin Res 2018;11:101-3.

15. US FDA, Guidance for Industry Bioanalytical Method Validation, Food and Drug Administration, Center for Drug Evaluation and Research (CDER), Rockville, Maryland, USA; 2001.

16. Marlina Ika, Rizka Andalusia, Supandi Supandi, Yahdiana Harahap. Simultaneous analytical method development of 6mercaptopurine and 6-methylmercaptopurine in dried blood spot using ultra performance liquid chromatography-tandem mass spectrometry. Int J Appl Pharm 2017;9:168-71.

17. Swathi P, Vidyadhara S, Sasidhar RLC, Kalyan Chakravarthi K. Method development and validation for the estimation of entecavir in bulk and pharmaceutical dosage forms by RPHPLC. Int J Curr Pharm Res 2017;9:107-11.

18. International Conference on Harmonization (ICH) of Technical Requirements for the Registration of Pharmaceuticals for Human Use, Validation of analytical procedures: Methodology, ICH-Q2B, Geneva; 1996.

19. Revathi Naga Lakshmi Ponnuri, Prahlad Pragallapati, Ravindra $\mathrm{N}$, Venkata Basaveswara Rao Mandava. A rapid and sensitive liquid chromatography-mass spectrometry/mass spectrometry method for estimation of pioglitazone, keto pioglitazone and hydroxy pioglitazone in human plasma. Asian J Pharm Clin Res 2017;10:120-8.

20. Validation of Analytical Procedures: Methodology. ICH Harmonised Tripartite Guidelines; 1995.

21. Rezk MR, Basalious EB, Karim IA. Development of a sensitive UPLC-ESI-MS/MS method for quantification of abacavir and its metabolite, GS-331007, in human plasma: application to a bioequivalence study. J Pharm Biomed Anal 2015;114:97-104.

22. Rezk MR, Basalious EB, Amin ME. Novel and sensitive UPLCMS/MS method for quantification of sofobuvir in human plasma: application to a bioequivalence study. Biomed Chromatogr 2016;30:1354-62.

23. Shi X, Zhu D, Lou J, Gan D. Evaluation of a rapid method for the simultaneous quantification of ribavirin, sofobuvir and its metabolites in rat plasma by UPLC-MS/MS method. J Chromatogr B: Anal Technol Biomed Life Sci 2015;1002:353-7.

24. Kobuchi S, Yano K, Ito Y, Sakaeda T. A validated LC-MS/MS method for the determination of canagliflozin, a sodiumglucose co-transporter 2 (SGLT-2) inhibitor, in a lower volume of rat plasma: application to pharmacokinetic studies in rats. Biomed Chromatogr 2016;30:1549-55.

25. Yahdiana Harahap, Norma Andriyani, Harmita. Method development and validation of lercanidipine in human plasma by liquid chromatography tandem mass spectrometry. Int J Appl Pharm 2018;10:87-91. 